\title{
MUJER Y VIOLENCIA. DIRECTRICES JURISPRUDENCIALES EN MATERIA DE DERECHOS HUMANOS*
}

\author{
Women and violence. Jurisprudential guidelines in Human
}

Rights

Mulher e violência. Diretrizes jurisprudenciais sobre direitos
humanos

\author{
Javier Oviedo Puig ${ }^{a}$ \\ jopuig@hotmail.com \\ Ramsés Montoya Camarena ${ }^{b}$ \\ ramgrrr@hotmail.com \\ Gabriela Aguado Romeroc \\ aguado.gabriela@hotmail.com
}

Fecha de recepción: 17 de febrero de 2020

Fecha de revisión: 18 de febrero de 2020

Fecha de aceptación: 22 de febrero de 2020

\section{DOI: http://doi.org/10.25058/1794600X.1702}

Para citar este artículo:

Oviedo, J., Montoya, R. y Aguado, G. (2020). Mujer y violencia. Directrices

jurisprudenciales en materia de derechos humanos. Revista Misión Jurídica, 13, (18), 83-96.

\section{RESUMEN}

La situación de violencia que se vive en México ha alcanzado niveles alarmantes y una de sus variantes, la que se ejerce contra la mujer, no ha disminuido su incidencia pese a ciertas acciones positivas realizadas en distintos ámbitos gubernamentales, ni se ha logrado, en los pocos casos que son judicializados y logran una sentencia condenatoria, una reparación del daño y restitución

\footnotetext{
* Artículo de investigación científica que presenta resultados de un proyecto de investigación en curso sobre Género, del grupo de Investigación Derechos Humanos de la Universidad Autónoma de Querétaro, Facultad de derecho (Proyecto realizado con financiamiento propio).

a. Abogado egresado de la Universidad Autónoma de Querétaro, Especialista en Derecho Penal. Candidato a Maestro en Derecho por la Universidad Autónoma de Querétaro, México. Profesor de la Facultad de Derecho de la Universidad Autónoma de Querétaro. Docente de la Procuraduría General de Justicia del Estado de Querétaro. Jefe de Departamento Comisionado en la Comisión Estatal del Sistema Penitenciario de Querétaro.

b. Abogado egresado de la Universidad Autónoma de Querétaro, Especialista en Derecho Constitucional y Amparo, con estudios de Maestría en Derecho por la Universidad Autónoma de Querétaro, México. Maestría en Argumentación Jurídica en la Universidad de Alicante, España; cuenta con el doble posgrado impartido en la Universidad de Palermo, Italia; en donde realizó una estancia de verano, con estudios de especialización y posgrado en Derechos Fundamentales por la Universidad Carlos III de Madrid. Doctor en Derecho por la Universidad Autónoma de Querétaro. Profesor de posgrado en diversas Universidades. Secretario de Tribunal Colegiado; Secretario de Estudio y Cuenta del Pleno del Vigésimo Segundo Circuito; Delegado estatal del Colegio Nacional de Secretarios del Poder Judicial de la Federación. Miembro del Sistema Nacional de Investigadores del Consejo Nacional de Ciencia y Tecnología (CONACYT), Nivel: Candidato.

c. Abogado egresado de la Universidad Autónoma de Querétaro, Especialista en Derecho Fiscal y en Derecho Notarial, con estudios de maestría y doctorado en derecho por la Universidad Autónoma de Querétaro, México. Miembro del Sistema Nacional de Investigadores del Consejo Nacional de Ciencia y Tecnología (CONACYT), Nivel: SNI I. Perfil deseable del Programa de Desarrollo Profesional Docente (PRODEP). Profesor Investigador de Tiempo Completo de la Facultad de Derecho de la Universidad Autónoma de Querétaro.
} 
a la víctima acorde a las disposiciones legales y estándares internacionales. El presente artículo expone a partir de datos estadísticos, el incremento de los índices de violencia contra la mujer, y tiene como objetivo pugnar por el incremento de la observancia en la actividad jurisdiccional de directrices jurisprudenciales relevantes en materia de derechos humanos, lo cual es útil para identificar las causas de violencia contra la mujer y tomar medidas de posible erradicación y reparación efectiva.

\section{PALABRAS CLAVE}

Mujer; violencia; jurisprudencia; derechos humanos; reparación.

\begin{abstract}
Violence in Mexico has reached disturbing levels where one of its variants, violence against women, hasn't decreased despite the positive actions that had been made in several government fields, nor has it been achieved, in the few cases are prosecuted and achieve a conviction, reparation of the damage and restitution to the victim according to legal provisions and international standards. The present article shows from statistic data; the increase in the index of violence against women, and its main objective the fight against the increase of the jurisdictional observance of jurisprudential guidelines relevant in the field of human rights, which is useful to identify the causes of violence against women and take actions for a further eradication and effective reparation.
\end{abstract}

\section{KEY WORDS}

Women; violence; jurisprudence; human rights; reparation.

\section{RESUMO}

A situação de violência vivida no México atingiu níveis alarmantes e uma de suas variantes, a exercida contra as mulheres, não diminuiu sua incidência, apesar de certas ações positivas realizadas em diferentes esferas governamentais. Este artigo demonstra a partir de dados estatísticos, o aumento das taxas de violência contra as mulheres e visa lutar pelo aumento da observância na atividade jurisdicional de diretrizes jurisprudenciais relevantes sobre direitos humanos, o que é útil para identificar causas de violência contra a mulher e tomar possíveis medidas de erradicação.

\section{PALAVRAS-CHAVES}

Mulher; violencia; jurisprudencia; direitos humanos; reparação.

\section{INTRODUCCIÓN}

El epicentro de la discusión jurídica gira alrededor de los derechos humanos. El peso de la validez material de los actos jurídicos depende del respeto a dichos derechos. La posibilidad de motorizar mejores condiciones de vida en todo el planeta supone un compromiso genuino para eliminar toda forma de violación de los derechos humanos. El paso fundamental para lograr este propósito comienza por erradicar las prácticas violentas.

En los últimos años, se ha registrado un aumento de la violencia, en especial la violencia intrafamiliar contra la mujer, con un toque a la alza de hasta el 64\%. En el Informe de 2018 de Latinobarómetro (2019) se identificó que la violencia contra la mujer se encuentra en segundo lugar en relación con las diversas formas de violencia.

México ha sido diagnosticado como uno de los países más violentos de los últimos años (Zepeda, 2018). Sus altos índices de violencia se reflejan en todos los escenarios de vida. ONU México (2018) reportó que al menos 6 de 10 mujeres mexicanas han enfrentado un incidente de violencia en su vida; igualmente, señaló que alrededor de 9 mujeres son asesinadas cada día.

Los datos consignan una pendiente ascendente de violencia contra la mujer que se enmarca en un escenario de violencia nacional. El refugio que se ha ofrecido apunta a la resignación, en virtud de que cualquier acción preventiva ha resultado ineficaz. Por tal motivo, este texto busca explorar y pugnar para que incremente la observancia y aplicación de los criterios jurisprudenciales en materia de violencia contra la mujer, la jurisprudencia desarrollada por la Corte Interamericana de Derechos Humanos ofrece una aproximación sensible sobre estas problemáticas y es necesario que los operadores jurídicos la conozcan y consideren en el desarrollo de su actividad, ya que esto conlleva a 
generar parámetros de identificación, sanción y reparación.

Ademas de cumplir con la obligación que toda autoridad tiene de abordar el problema desde la óptica de los derechos humanos, buscando el respeto, promoción, protección y garantía de los mismos.

\section{METODOLOGÍA}

Para el desarrollo de presente artículo se hizo uso del método analítico, así como la utilización del método de la proyección, perspectiva y prospectiva, toda vez que estos nos permiten un acercamiento a una situación de futuro deseada, para esto se realizó una revisión y comparación de datos estadísticos, se analizó la legislación convencional y la jurisprudencia respectiva, además fueron de utilidad los métodos dogmático, deductivo y sintético, bajo la utilización de la técnica de la investigación documental.

\section{VIOLENCIA CONTRA LA MUJER Y LOS DERECHOS HUMANOS}

Los derechos humanos, en tanto construcción humana, nacen cuando deben o cuando pueden, dice Bobbio. El jurista italiano también ha señalado que el problema real de los derechos humanos es el de las medidas pensadas y pensables para su efectiva protección (1991: 7075). Hoy es latente la necesidad de hacer posible esa protección frente al adverso escenario de violencia que se atraviesa en todas las fronteras del mundo.

En efecto, las cifras sobre desigualdad comienzan por la violencia. A nivel mundial los datos son alarmantes. Algunos de ellos, consignan la cantidad de mujeres que mueren por cada 100,000 niños nacidos vivos: Entre 3 y 5 mujeres en Finlandia, Islandia, Italia, Noruega, España, Suiza, Grecia, Japón, en países con más alto índice de desarrollo humano en el mundo. Entre 94 a 124 en países como Panamá, República Dominicana y Tonga. Entre 206 hasta 510 en países con desarrollo humano medio, como Bolivia, Guinea Ecuatorial y Kenya. De 602 hasta 1,360 mujeres muertas, en países con desarrollo humano bajo, entre los que se encuentran Costa de Marfil, Liberia, República Centroafricana, Sierra Leona, etcétera (Banco Mundial, 2019).
ONU Mujeres (2017) publicó importantes datos sobre el feminicidio en el país. Los datos muestran una cultura violenta, misógina y empobrecida de justicia, en la que la mayoría de las mujeres, sin distinción de edad, han sufrido algún tipo de violencia, en especial la que ha sido calificada como la más grave por el Comité de la Convención sobre la Eliminación de Todas las Formas de Discriminación contra la Mujer: el feminicidio, que se traduce en una extendida y arraigada forma de conservar y reproducir el sometimiento y subordinación de la mujer en las relaciones de poder. La información que brinda es sobre defunciones femeninas con presunción de homicidio.

Los datos parten de la información disponible; de ahí que en cierta medida debe existir un grado de falibilidad estadístico, porque en ocasiones se desconoce la identidad del victimario o su relación con la víctima, lo que hace suponer que hay deficiencias en las investigaciones. Además que existe una actitud recurrente de las autoridades por no brindar toda la información sobre el hallazgo del crimen, al amparo de que no se cuentan con los datos desagregados o los datos son confidenciales o reservados. En fin, con esta reserva aún se pueden observar datos alarmantes.

De entrada, se revela que en 32 años del muestreo (1985-2016) realizado por ONU Mujeres (2017:19-20), han ocurrido 52,210 muertes de mujeres en que se presume el homicidio, de las cuales 15,535 son registradas en los últimos 6 años, entre 2010 y 2016. Las cifras más altas están en 2012, con 2,769 muertes, y 2016, con 2,746 decesos. La tendencia que se observa de los registros demuestra que en 1988 y 1998 hubo una reducción con ligeros repuntes con respecto a las tasas del año anterior; sin embargo, de 2007 en adelante, cuando hasta ese momento la tasa de muertes se había reducido alrededor de la mitad (1,089 muertes que representa el 1.9\% de defunciones por cada 100,000 mujeres) ahora presenta un repunte del 138\%; esto significa que no solo se perdieron los avances logrados en los 23 años anteriores, sino también que ahora se incrementaron los registros a niveles que antes no se habían documentado.

El factor de incremento supone que la cifra de 2016 implica un promedio de 7.5 asesinatos de mujeres por día. La información comprende un comportamiento diferenciado no solo en el aumento de las muertes, sino también en su 
mayor resistencia al descenso, lo cual sugiere una conducta específica de violencia contra las mujeres, de acuerdo a las variaciones porcentuales, en particular para los últimos años, el indicador consiste en que una razón explicativa de los asesinatos de mujeres obedece al acto discriminatorio que precede a la agresión letal, en particular la denominada violencia social vinculada con el crimen organizado, cuyo fenómeno se ha agravado en México a partir de 2007.

De la geografía del feminicidio se derivan números de extrema preocupación; siendo factible señalar, como ejemplos, a Colima, donde se registra la mayor tasa de 2016 con 16.3 defunciones femeninas con presunción de homicidio por cada 100,000 mujeres; le siguen Guerrero con 13.1, Zacatecas con 9.7, Chihuahua con 8.8 y Morelos con 8.4. Estos son los cinco lugares donde, presuntamente, más se asesinan mujeres en México. Por otra parte, el mayor número de defunciones anual lo tiene el Estado de México con 421, en segundo lugar viene Guerrero con 243, después está Chihuahua con 168 y, luego, la Ciudad de México con 144 (ONU Mujeres, 2017: 24).

En otra lectura, en el Estado de México han ocurrido 15\% de los asesinatos de mujeres en los últimos diez años, esto resulta congruente porque es la entidad más poblada del país, además, entre 2010 y 2015 concentró $13.5 \%$ de la población femenina de la nación. Sin embargo, cabe resaltar que mientras Chihuahua concentra $10.5 \%$ de las defunciones femeninas, solo tiene el $3 \%$ del total de la población femenina en los mismos años. La revisión de las muertes ocurridas según el municipio, colocan en primer lugar a Acapulco de Juárez en los años 2012, 2013, 2015 y 2016, excepto en 2011, cuando lo registró Ciudad Juárez y en 2014, cuando, según el diagnóstico, correspondió a Ecatepec de Morelos (INMUJERESSEGOB, 2017: 17-40).

Para sumar datos, la Encuesta Nacional sobre la Dinámica de las Relaciones en los Hogares (ENDIREH, 2016: 13-16), ofrece información para identificar el tipo de violencia contra la mujer y el ámbito en que esta se manifiesta. En la encuesta, se establece que de la muestra representativa de 142,363 viviendas y el periodo de tiempo establecido, que comprende de 2015 a 2016, en el ámbito escolar por tipo de violencia, las mujeres de 15 años y más que han experimentado violencia en la escuela, a lo largo de su vida de estudiante, equivale a un $16.7 \%$ con algún tipo de violencia física, un $10.9 \%$ con violencia sexual y un $10.4 \%$ con violencia emocional; en tanto que un $6.3 \%$ reportó violencia física en los últimos 12 meses del periodo de referencia, un $10.7 \%$ violencia sexual y un $7.8 \%$ violencia emocional. De acuerdo con el estudio, Querétaro presentó el mayor número de casos, proporcionalmente hablando, entre un $32.5 \%$ de la muestra, ante una media nacional de $25.3 \%$.

Como agresores en el ámbito escolar, se identificaron en los últimos 12 meses del periodo de referencia, a los compañeros en un $47.1 \%$; compañeras en un $16.6 \%$; maestros en un $11 \%$; persona desconocida de la escuela $14 \%$; otra persona de la escuela $6.5 \%$; maestra 1.4\%; trabajador de la escuela $2.2 \%$; director o directora $0.9 \%$ y trabajadora de la escuela $0.3 \%$. En su vida académica en general, se identificaron a los compañeros en un 39.9\%; compañeras en un $20.1 \%$; maestros en un $14.4 \%$; persona desconocida de la escuela $11.9 \%$; otra persona de la escuela 5.4\%; maestra 5\%; trabajador de la escuela 1.8\%; director o directora $1.1 \%$ y trabajadora de la escuela $0.3 \%$.

En cuanto a los lugares donde ocurre la violencia escolar, un $74.3 \%$ refirió a la escuela como el sitio donde ocurre; un $15.9 \%$ la calle, parque o lugar público cerca de la escuela; un $5.7 \%$ señaló la calle, parque o lugar público lejos de la escuela; un $1.8 \%$ el transporte público; un $1.5 \%$ una casa particular y un $0.8 \%$ refirió otros lugares. Entre los tipos de agresiones ocurridas en la escuela, un $38.3 \%$ refirió que la agresión era de tipo sexual; un $34.1 \%$ agresión de tipo emocional y física un $27.7 \%$.

Los datos referidos, ponen en relieve que el espacio público y el escolar, son escenarios en los que constantemente hay exposición a la violencia para la mujer. Sin embargo, es evidente que la violencia hacia las mujeres es un fenómeno generalizado, que está presente en todas las clases sociales, grupos étnicos y edades; y que acontece en la casa, en la calle, en el trabajo y se manifiesta en agresiones sexuales, físicas, psicológicas, patrimoniales y económicas, de lo que se deduce que se trata de un problema multifactorial que afecta no solo a las mujeres que la padecen, sino a las familias y sociedad. 
En las Observaciones finales sobre el noveno informe periódico de México, el Comité para la Eliminación de la Discriminación contra la Mujer lamentó, nuevamente, que persistan altos niveles de inseguridad, violencia y delincuencia organizada. De igual forma, hizo un llamado sobre el hecho que las estrategias de seguridad pública afecten negativamente el ejercicio de los derechos de mujeres y niñas.

En materia de violencia de género, el Comité expresó preocupación por varias razones, entre ellas, las siguientes: a) el uso de patrones generalizados de violencia por razón de género (física, psicológica, sexual y económica) y aumento de la violencia doméstica, desapariciones forzadas, tortura sexual, asesinatos, en especial de los feminicidios; b) la participación de agentes estatales y no estatales en dichos delitos; c) la incidencia de la desaparición forzada, en tanto víctimas directas como indirectas, dado que las mujeres suelen llevar la carga de buscar a la persona desaparecida, motivar las investigaciones y servir de sostén principal de la familia; d) las barreras que persisten para implementar la alerta de violencia de género; e) las constantes denuncias de violencia cometida en contra de mujeres lesbianas, bisexuales y transgénero; f) la escasa recopilación de datos estadísticos debidamente desglosados, etcétera.

En gran medida, las recomendaciones del Comité se orientan en reiterar recomendaciones pasadas, con el objeto de atender y prevenir diversos delitos, entre ellos, los ajustes normativos sobre el feminicidio y la oportuna investigación en las desapariciones forzadas, con la finalidad de sancionar de forma prioritaria a los responsables. También señala que debe simplificarse y armonizarse el mecanismo para la alerta de género que agilice la búsqueda de mujeres y niñas desaparecidas e, igualmente, recomendó subsanar las deficiencias en la protección de la dignidad de las mujeres lesbianas, bisexuales y transgénero $\mathrm{y}$, finalmente, la necesidad de recopilar de forma sistemática los datos de violencia correspondiente (CEDAW/C/MEX/CO/9, 2018: 8 y 9).

En tal sentido, entre algunas de sus recomendaciones, el Comité para la Eliminación de la Discriminación contra la Mujer estableció lo siguiente:

[...] 10. El Comité reitera sus recomendaciones

anteriores (CEDAW/C/MEX/CO/7- 8, 2012: párr. 12) e insta al Estado parte a que: - - a) Refuerce su estrategia de seguridad pública para luchar contra la delincuencia organizada, en cumplimiento de sus obligaciones internacionales en materia de derechos humanos, incluidas las derivadas de la Convención, y acabe con los altos niveles de inseguridad y violencia que siguen afectando a las mujeres y las niñas; - - - [...] - - - De conformidad con las obligaciones que incumben al Estado parte en virtud de la Convención, en consonancia con la meta 5.1 de los Objetivos de Desarrollo Sostenible, que es poner fin a todas las formas de discriminación contra todas las mujeres y las niñas en todo el mundo, y teniendo en cuenta la labor positiva realizada por el Estado parte al aprobar otras leyes generales, el Comité recomienda al Estado parte que: - - [...] - - c) Establezca un mecanismo de denuncia judicial específico para los casos de discriminación contra las mujeres y vele por que se asignen los recursos humanos, técnicos y financieros necesarios para su aplicación efectiva, que entraña capacitar a la judicatura sobre la aplicación de la Convención y otras leyes de lucha contra la discriminación; - - [...] - - 14. De conformidad con la Convención y con su recomendación general núm. 33 (2015), sobre el acceso de las mujeres a la justicia, el Comité recomienda al Estado parte que: - - - a) Vele por que se capacite, de manera sistemática y obligatoria, a los jueces, los fiscales, los defensores públicos, los abogados, los agentes de policía y otros funcionarios encargados de hacer cumplir la ley, en los planos federal, estatal y local, acerca de los derechos de la mujer y la igualdad de género, para poner fin al trato discriminatorio de que son objeto las mujeres y las niñas; - - [...] - - d) Aliente a las mujeres a denunciar los incidentes de violencia de género, incluida la violencia doméstica, se asegure de que las mujeres víctimas de discriminación y violencia de género tengan acceso a recursos efectivos y oportunos, y garantice que todos los casos de violencia de género contra la mujer se investiguen eficazmente $\mathrm{y}$ que los autores sean enjuiciados y castigados como corresponda. - - 24. El Comité recuerda su recomendación general núm. 35 (2017) sobre la violencia por razón de género contra la mujer, por la que se actualiza la recomendación general núm. 19, y reitera su recomendación al Estado parte de que: - - - a) Adopte medidas de carácter urgente para prevenir las muertes violentas, los asesinatos y las desapariciones forzadas de mujeres, en particular combatiendo las causas profundas de esos actos, como la violencia 
armada, la delincuencia organizada, el tráfico de estupefacientes, los estereotipos discriminatorios, la pobreza y la marginación de las mujeres; - - - b) Investigue, enjuicie y sancione como corresponda a los responsables, incluidos los agentes estatales y no estatales, como cuestión prioritaria; - - - [...] - - - f) Subsane la falta de medidas de protección de la dignidad y la integridad de las mujeres lesbianas, bisexuales y transgénero, en particular concienciando a la población sobre los derechos de estas mujeres, en cooperación con la sociedad civil; - - - g) Refuerce los mecanismos de recopilación sistemática de datos sobre la violencia contra las mujeres y las niñas, incluidos los feminicidios, y las desapariciones forzadas, desglosados por tipo de violencia y relación con los perpetradores [...] (CEDAW/C/MEX/CO/9, 2018: 1-10).

Las anteriores recomendaciones apuntan hacia seis problemas específicos: a) los obstáculos que existen en materia de seguridad pública, violencia y acceso a la justicia para mujeres y niñas; b) la falta de capacitación en materia de perspectiva de género, para que los operadores jurídicos, en especial los de la judicatura, puedan aplicar adecuadamente los materiales normativos y tratados internacionales sobre lucha contra la discriminación en perjuicio de mujeres y niñas; c) la falta de incentivos, sensibilización y concientización para motivar la denuncia de violencia de género, especialmente la violencia doméstica, para lo cual debe garantizarse la investigación y enjuiciamiento eficaz de los responsables; d) la necesidad de adoptar medidas de carácter urgente, para prevenir el feminicidio $\mathrm{y}$, combatir las causas profundas que generan esa violencia; e) la falta de investigación adecuada de la violencia como una cuestión prioritaria y f) la falta de datos desagregados y su recopilación, para advertir cuáles son las condiciones de la violencia de género y, el desglose de datos en función de los perpetradores.

La Suprema Corte de Justicia de la Nación, en un esfuerzo por eliminar las situaciones detectadas en el Diagnóstico Diversificado realizado al interior de la Corte entre 2008 y 2009 , en el que se encontró que aun cuando el personal de la Corte consideraba importante incluir la perspectiva de género en el análisis de los asuntos de su conocimiento, un porcentaje importante no saben qué es la perspectiva de género o no tienen una idea idónea de lo que ello implica. A raíz de lo anterior emitió el Protocolo para Juzgar con Perspectiva de Género, documento dirigido a quienes imparten justicia a nivel federal y estatal, y todas aquellas personas e instituciones involucradas en los procesos de acceso a la justicia (Suprema Corte de Justicia de la Nación, 2015: 9).

Sin embargo, las cifras no han sufrido variantes significativas por cuanto ese tipo de documentos no permean en todas las estructuras gubernamentales y sociales, lo cual incide de manera negativa en la efectividad de las autoridades para identificar, tipificar y sancionar hechos que constituyen violencia contra las mujeres.

Lo anterior, se advierte en hechos tan recientes como la marcha contra la violencia de género del 17 de agosto de 2019 y los datos contenidos en la Información sobre violencia contra las mujeres del Secretariado Ejecutivo del Sistema Nacional de Seguridad Pública, con corte al 30 de septiembre de 2019, que contiene información sobre violencia contra las mujeres de acuerdo a las bases de datos de Incidencia delictiva y llamadas de emergencia al número 9-1-1, proporcionada por las procuradurías y fiscalías generales de los estados. De esto se deduce que se trata de carpetas de investigación iniciadas por hechos probablemente constitutivos de delito que, posiblemente habían modificado su clasificación con la investigación posterior, lo que no le resta valor, pues solo implicaría una reclasificación (Secretaria de Seguridad Ciudadana, 2019: 8)

Con relación a las llamadas de emergencia al número 9-1-1, el informe especifica que no se trata de denuncias ante autoridad, sino de reportes de alguna percepción de emergencia de acuerdo al criterio de quien realiza el reporte.

No obstante, los datos que evidencia el informe son reveladores: del universo de delitos registrados de enero a septiembre de 2019, cometidos a 84,600 presuntas víctimas mujeres, el $60.19 \%$ corresponde a lesiones dolosas, el homicidio doloso a un $2.49 \%$, el feminicidio a un $0.88 \%$, la corrupción de menores a un $1.32 \% \mathrm{y}$, finalmente, la trata de personas un $0.33 \%$.

La tendencia nacional del presunto delito de feminicidio se ha incrementado en los últimos 5 años, pasando de 411 en 2015 a 602 en el 2016, 742 en 2017, 885 en 2018 y a 726 en 2019, faltando por registrar en el momento de esta 
investigación lo que acontezca en de octubre a diciembre, por lo que se revela una tendencia al alza inequívoca, es decir 1.12 feminicidios por cada cien mil mujeres como media nacional.

Lo mismo ocurre con el delito de homicidio doloso en agravio de víctimas mujeres pues, de acuerdo a las cifras, en 2015 se cometieron 1.735 homicidios, 2190 en 2016, 2535 en 2017, 2777 en 2018 y hasta el mes de septiembre de 2019, 2107 casos. Cifras preocupantes que implican una media nacional de 2107 homicidios dolosos por cada cien mil mujeres.

La tendencia al alza se repite en el delito de lesiones dolosas que, como se ha mencionado, es el de mayor incidencia en contra de las mujeres, puesto que en el año 2015 se registraron 56.422 lesiones, 51.336 en 2016, frente a 65.797 en 2017, a lo que siguió una leve disminución a 61.899 hechos en 2018, pero registrándose hasta el mes de septiembre de 2019, un total de 50.923 casos, que, al promedio anual de 5.658 casos por mes, alcanzaría, de mantenerse la tendencia, un alarmante número de 67.897 casos de lesiones dolosas en agravio de mujeres. Lo anterior equivale a una media nacional de 78.8 hechos por cada cien mil mujeres.

Si atendemos a la definición de impunidad contenida en el Conjunto de principios actualizado para la protección y la promoción de los derechos humanos mediante la lucha contra la impunidad (2005) emitido por la Comisión de Derechos Humanos de la Organización de Naciones Unidas, que la define como la inexistencia, de hecho o de derecho, de responsabilidad penal por parte de los autores de violaciones, así como de responsabilidad civil, administrativa o disciplinaria, porque escapan a toda investigación con miras a su inculpación, detención, procesamiento $\mathrm{y}$, en caso de ser reconocidos culpables, condena a penas apropiadas, incluso a la indemnización del daño causado a sus víctimas; es evidente que las cifras referidas visibilizan una situación de impunidad con relación a la violencia contra la mujer pues de éstas se desprende que existe una resistencia y temor de las mujeres violentadas a denunciar pues perciben esas actividades como procesos de revictimización, no reciben medidas de protección efectivas y desconocen los derechos que les asisten y sobre todo, el derecho que tienen a una vida libre de violencia.
El escenario descrito activa una alarma preventiva y de reacción frente a la violencia y la desigualdad estructural. De este modo, la jurisprudencia se plantea como una acción concreta de transformación para aquellas personas que viven al margen del bienestar y la fragmentación social producto de la violencia. $\mathrm{Su}$ conformación representa una forma de desinstitucionalizar el fenómeno regresivo de violencia y exclusión. Desde la comparativa fáctica entre los grupos más afectados por la violencia se encuentra la mujer, de modo que la opresión o violación de sus derechos hace que la protección frente a la desigualdad sea en un espectro restrictivo $\mathrm{y}$, por ende, es necesario identificar los brazos jurídicos que ofrece la jurisprudencia para paliar esta situación.

\section{UNA APROXIMACIÓN JURISPRUDENCIAL PARA ERRADICAR LA VIOLENCIA}

El derecho interno de los Estados, en el caso, la Constitución Política de los Estados Unidos Mexicanos y las leyes que de ella emanen, ha dejado de ser el único mecanismo de protección de los derechos humanos, ya que la protección de estos se sustenta también en los tratados internacionales de los que México sea parte. En este contexto, la adhesión de nuestro país a la Convención Americana de Derechos Humanos de 2 de marzo de 1981, abre la puerta al sistema de protección de los derechos humanos, aceptando la competencia de los órganos encargados de su aplicación e interpretación, entre los que se encuentra, desde luego, la Corte Interamericana de Derechos Humanos, que tiene entre sus funciones más relevantes se encuentran la adopción de opiniones consultivas y el examen de casos contenciosos, de cuya sustanciación, se tiene como resultado la emisión de sentencias que determinan la aplicación e interpretación de la Convención Americana de Derechos Humanos, lo que constituye la jurisprudencia de la Corte Interamericana de Derechos Humanos.

La jurisprudencia en este tema ha surgido gracias a que los derechos de las mujeres han sido exigidos de manera constante a lo largo de los últimos años. De esta forma los problemas que las afectaban, con hondas grietas y profundos sufrimientos, han motivado una reacción vigorosa desde la Corte Interamericana de Derechos Humanos; en donde se han construido estándares 
importantes de garantía y protección de los derechos de las mujeres.

Enseguida, se mencionan algunos casos, tanto en los que la violación de derechos ha sido en perjuicio de mujeres, como aquellos en que la violencia sobre la mujer ha sido tratada como un problema que debe enfrentarse con perspectiva de género. Así, la ilación continua de la forma en que la Corte Interamericana de Derechos Humanos ha conformado su jurisprudencia, permitirá detectar rubros comunes de avances y aislar datos que, a la postre, dejan ver que, con la inclusión del parámetro de género en el análisis, se han construido patrones de transformación socio-cultural desde la jurisprudencia.

a) El Caso Loayza Tamayo vs. Perú se finca por el arresto sin orden judicial de María Elena Loayza Tamayo, profesora de la Universidad de San Martín de Porres, por la División Nacional contra el Terrorismo, por supuesta colaboración con el grupo denominado Sendero Luminoso. En ese caso, se analizaron cuestiones sobre violación al debido proceso y a las garantías judiciales, por doble enjuiciamiento. Hubo dos aspectos fundamentales en la sentencia. La primera cuestión fue que se rechazó la invocación de obstáculos de derecho interno, para la investigación y enjuiciamiento de los responsables. La segunda consistió en que, por primera vez en materia de reparaciones, se abordó lo relativo al daño al plan de vida (Corte IDH., Caso Loayza Tamayo. vs. Perú, Sentencia de 17 de septiembre de 1997: Serie C. No. 33).

b) El Caso Benavides Cevallos vs. Ecuador surgió por la detención arbitraria de la profesora Consuelo Benavides Cevallos, su incomunicación, tortura y asesinato, por miembros de la Infantería Naval, los que adujeron la participación de la víctima en un grupo guerrillero. En ese asunto, el Estado parte reconoció su responsabilidad internacional de los hechos (Corte IDH, Caso Benavides Cevallos. vs. Ecuador, Sentencia de 19 de junio de 1998: Serie C. No. 38).

c) El Caso Myrna Mack Chang vs. Guatemala se suscitó con motivo de la ejecución extrajudicial de Myrna quien, como antropóloga, se dedicaba al estudio de la problemática que atravesaban los refugiados en una época de gran violencia interna en Guatemala. Su asesinato ocurrió dentro de una operación de inteligencia militar con participación del Estado Mayor Presidencial (Corte IDH, Caso
Myrna Mack Chang vs. Guatemala, Sentencia de 25 de noviembre de 2003: Serie C. No. 101).

d) En el Caso Maritza Urrutia vs. Guatemala se retuvo a la víctima en un lugar de detención clandestina; igualmente, se le obligó a emitir un comunicado con motivación política, el cual fue preparado por sus captores. En el asunto, hubo pronunciamiento acerca de tortura psicológica por intimidación, retención prolongada y amenazas en contra de la víctima (Corte IDH, Caso Maritza Urrutia vs. Guatemala, Sentencia de 27 de noviembre de 2003: Serie C. No.103).

e) En el Caso De La Cruz Flores vs. Perú, una doctora inculpada de terrorismo fue juzgada por un tribunal sin rostro. En ese caso, además de delimitarse el poder de tipificación penal por parte del Estado, también se abordaron cuestiones sobre el deber facultativo de denunciar a pacientes que hubiesen incurrido en conductas delictivas, en función de las obligaciones inherentes al cuidado profesional de la salud (Corte IDH, Caso de la Cruz Flores vs. Perú, Sentencia de 18 de noviembre de 2004: Serie C. No. 115).

f) El Caso de las Hermanas Serrano Cruz vs. El Salvador lo motivó la captura, traslado y desaparición de dos hermanas menores de edad, dentro de la denominada "operación limpieza" o "La Guinda de Mayo". La privación de la libertad y el reconocimiento del sufrimiento causado a los familiares fue materia del estudio por parte de la Corte Interamericana (Corte IDH, Caso de las Hermanas Serrano Cruz vs. El Salvador, Sentencia de 1 de marzo de 2005: Serie C. No.120).

g) El Caso del Penal Castro Castro vs. Perú surge del señalamiento de que el Estado causó la muerte de al menos 42 internos, lesionó a 175 y maltrató a cerca de 322 de ellos dentro del Penal Miguel Castro Castro. En materia de violencia contra la mujer, se identificó que las mujeres estuvieron sujetas a distintos tipos de violencia, incluida la de índole sexual, a través de revisiones o inspecciones vaginales, desnudez forzada, manoseos, insultos de connotación sexual, golpes en senos, piernas y glúteos; al igual que golpes en el vientre a mujeres embarazadas.

La relevancia del caso se concentra especialmente en que la Corte profundizó en cuatro temáticas de importancia: a) estableció el alcance del concepto discriminación de la 
mujer; b) determinó la protección especial de la mujer en reclusión, con énfasis a las madres y embarazadas; c) calificó como tortura la desnudez forzada y la inspección vaginal y, finalmente, d) desarrolló algunas directrices para considerar los contextos de las víctimas y, a partir de ello, fijar el monto de indemnización en materia de reparaciones. Aquí la consideración del abuso del poder de los agentes jugó un punto determinante para desarrollar dicho análisis (Corte IDH, Caso del Penal Miguel Castro Castro vs. Perú, Sentencia de 25 de noviembre de 2006: Serie C. No. 160).

h) En el Caso González y otras ("Campo Algodonero") vs. México se juzga por la desaparición y muerte de tres mujeres jóvenes, cuyos cuerpos fueron encontrados en un campo algodonero con significativas huellas de violencia. La Corte Interamericana manda un mensaje potente al sostener que existe en México un patrón de violencia de género que había dejado a mujeres y niñas asesinadas. La sentencia identifica las falencias en la investigación de los hechos y la omisión de adoptar las medidas con la diligencia requerida, para impedir la violación de derechos, en particular aquellas cuestiones en que se implicaban estereotipos de los agentes $y$, a partir de lo cual, se generaba un mensaje de perpetuación de la violencia contra la mujer en Ciudad Juárez.

En ese sentido, se identificó que este tipo de conductas representa también una discriminación en el acceso a la justicia, con la consecuente situación de impunidad que deriva. En materia de reparación, la Corte introdujo la necesidad de que las investigaciones se desarrollaran con perspectiva de género, para indagar sobre la violencia sexual y los patrones de la zona que importaran a los casos. Incluso, en materia de búsqueda de desaparecidos dispuso que las autoridades deben asignar los recursos humanos, económicos, logísticos, científicos o de cualquier índole que sean necesarios para el éxito de la búsqueda; lo cual habría de ser más riguroso y urgente cuando la desaparecida sea una niña. Igualmente, se ordenó la implementación de cursos en materia de derechos humanos a fin de que las investigaciones y procesos judiciales superen los estereotipos discriminatorios (Corte IDH, Caso González y otras ("Campo Algodonero"). vs. México, Sentencia de 16 de noviembre de 2009: Serie C. No. 205). i) El Caso de la Masacre De Las Dos Erres vs. Guatemala se enfocó en juzgar la masacre de 251 habitantes del Parcelamiento de las Dos Erres ocurrida en 1982. Se alegó que la masacre fue ejecutada por elementos del grupo especializado de las fuerzas armadas de Guatemala llamados kaibiles, en donde se encontraban mujeres que habrían sido violadas y golpeadas hasta el punto de sufrir abortos. Debido a que la competencia de la Corte Interamericana entró en vigor cinco años después de los hechos, el tribunal indicó, que si bien no podía referirse a los hechos de violencia, sí podía conocer sobre la falta de investigación efectiva de esos hechos. Igualmente, se retomó por parte de la Corte, la jurisprudencia sobre tortura y violencia sexual en conflictos armados o patrones sistemáticos de violencia, para indicar que son graves violaciones de derechos humanos que contravienen normas inderogables (ius cogens) y generan obligaciones a los Estados parte, de investigar y juzgar los hechos. En materia de reparaciones, se explicó que debía tomarse en cuenta el patrón sistemático de la violencia en la época que sucedieron los hechos a la luz de los impactos diferenciados con motivo de la violencia contra la niñez y la mujer (Corte IDH, Caso de la Masacre De Las Dos Erres vs. Guatemala, Sentencia de 1 de marzo de 2005: Serie C. No. 120).

j) El Caso Fernández Ortega y otros vs. México denuncia la violación y tortura de víctimas a manos del Ejército mexicano. La Corte puso énfasis en que los hechos habían ocurrido en un contexto de presencia militar dirigida a reprimir la delincuencia organizada y, que las acciones perpetradas habían ocurrido en perjuicio de comunidades indígenas, la cual se encontraba en condición de vulnerabilidad, quienes encontraban serias dificultades para acudir a los órganos de justicia o de protección de sus derechos, bien por miedo, desconfianza o imposibilidad económica, incluso de comunicación por no hablar español.

La Corte pudo orientar varias líneas de estudio interesantes sobre distintos temas, entre ellos, el estándar de prueba en casos de violación sexual, la violación sexual como acto de tortura, la violación sexual como afectación de la dignidad humana, etcétera. En materia de reparaciones, se ordenó que la investigación de la violencia sexual quedara bajo la jurisdicción civil, no en el fuero militar, para lo cual, los jueces habrían de realizar un control de convencionalidad y los legisladores adecuar el derecho interno a los estándares interamericanos. 
Asimismo, la Corte refrendó la necesidad de que las investigaciones se desarrollaran desde una perspectiva de género, en donde se consideraran las circunstancias de especial vulnerabilidad, como lo era precisamente, la característica y cosmovisión indígena de las víctimas (Corte IDH, Caso Fernández Ortega y otros vs. México, Sentencia de 24 de noviembre de 2009: Serie C. No. 211).

k) El Caso Rosenda Cantú y otra vs. México también denuncia la violación y tortura de víctimas a manos del Ejército mexicano, con la diferencia de que Rosenda Cantú era menor de edad cuanto acontecieron los hechos. El contexto es similar al caso anterior. La Corte pudo profundizar en que, en casos de violencia sexual, no se puede esperar la existencia de pruebas gráficas o directas, de modo tal que la declaración de la víctima constituye una prueba fundamental sobre el hecho. En el tema de tortura, se tomó de referencia que ésta se revela por la intencionalidad, la severidad del sufrimiento y la finalidad del acto, tendente a la subordinación sexual de la violación.

También se indicó que la violación de la dignidad humana se hace patente por la anulación a la libre decisión de con quien tener relaciones sexuales, de modo tal que se pierde el control absoluto sobre las decisiones más personales e íntimas y, sobre las propias funciones corporales más básicas. En materia de protección especial, se explicó que el interés superior de la infancia debe tutelarse en cualquier procedimiento judicial, a fin de asegurar que los niños y niñas víctimas sean escuchados, garantizando que el personal esté debidamente preparado para atenderles y, adaptar los procesos a las necesidades particulares de las víctimas, incluso, para evitar que sea interrogadas en más ocasiones que las necesarias, para evitar la revictimización (Corte IDH, Caso Rosenda Cantú y otra vs. México, Sentencia de 31 de agosto de 2010: Serie C. No. 216).

El apretado resumen, da cuenta de aspectos fundamentales que ha tratado la Corte Interamericana sobre violación de derechos de la mujer. Pasa desde el debido proceso hasta cuestiones de intimidación, incomunicación, tortura, violencia sexual, desaparición forzada, privación de la libertad y privación de la vida que han sufrido mujeres, niñas, adolescentes, indígenas, etcétera. Desde estas plataformas contenciosas, el tribunal internacional se ha ocupado de construir distintas directrices que importan, fundamentalmente a tres aspectos: (i) el acceso a la justicia, (ii) la calificación y valoración de los hechos, y (iii) los alcances de las medidas de reparación; en tanto que en ellos ha impulsado, como medida general, la obligación que se tiene de resolver tales cuestiones desde la perspectiva de género.

En consonancia con lo anterior, a continuación se identifica qué directrices ha establecido la Corte Interamericana en esos temas, a fin de hacerlos mucho más accesibles a los casos que pueden tener impacto en sede nacional, con el objeto de que el análisis con enfoque de género, permita generar un impulso transformativo desde los patrones de interpretación hasta los patrones culturales de discriminación por razón de género.

\section{DIRECTRICES JURISPRUDENCIALES DE LA CORTE INTERAMERICANA DE DERECHOS HUMANOS QUE ORIENTAN A SOLUCIONES CON PERSPECTIVA DE GÉNERO}

La jurisdicción de la Corte IDH constituye un medio eficiente para enfrentar la realidad de violencia que atraviesan las mujeres en América Latina y, específicamente, en México. $\mathrm{Su}$ jurisprudencia evolutiva ha consolidado tres líneas de focalización que orientan a las jurisdicciones nacionales para identificar y fortalecer aquellos fallos en los que es necesario combatir los patrones y rasgos estructurales de desigualdad, hacia un horizonte en el que se termine con la impunidad, en particular, como se ha dicho, en el acceso a la justicia, la calificación y valoración de los hechos, y los alcances de las medidas de reparación. En estos ejes transversales hay patrones compartidos que sirven de directriz para los casos acontecidos en América Latina en general, y en México en particular, cuando la situación amerite una solución con enfoque de género.

\subsection{Evitar obstáculos o discriminación en el acceso a la justicia}

La Corte Interamericana ha establecido, de manera enfática, que las autoridades deben superar los obstáculos del derecho interno para enjuiciar los actos violatorios de derechos humanos; de modo tal que se evite perpetuar 
un acceso limitado a la tutela judicial. Esto para evitar un ejercicio discriminatorio en perjuicio de la mujer, en la medida en que debe tomarse en cuenta el contexto de la persona y su especial situación de vulnerabilidad (por ejemplo, tratándose de reclusas, madres o embarazadas, quienes ameritan una protección reforzada).

Se consuma, igualmente, que las investigaciones en México deben adoptarse con diligencia, para evitar la eventual violación de derechos $y$, además, con un enfoque de género para evitar la reproducción de estereotipos que validen el mensaje de perpetuar la violencia contra la mujer; en virtud de que ello, en última instancia, constituye una forma de impunidad y restricción en el acceso a la justicia.

En los casos contra México se identificaron tanto la conexión de la presencia militar en regiones indígenas como la puesta en peligro de las mujeres, observando la especial vulnerabilidad que, para ellas, por distintas razones (miedo, desconfianza, imposibilidad económica o idioma), involucra acudir ante un órgano de justicia o de protección de derechos,.

Se impone que la violencia sexual quede bajo la jurisdicción civil, no en el fuero militar, con el fin que los jueces garanticen ese acceso a la justicia. Incluso se ordenó que los jueces realizaran un control de convencionalidad y se ordenó a los legisladores que adecuaran el derecho interno conforme a los estándares interamericanos.

\subsection{Estándar de prueba en violencia y actos genuinos de tortura}

La jurisprudencia interamericana ha ampliado el panorama bajo el cual se comprendía la violencia de género, al grado de reconocer la existencia de tortura cuando existe intimidación, retención prolongada, amenazas, insultos, golpes, violencia sexual (revisión o inspecciones vaginales, desnudez forzada, manoseos, etcétera); en lo cual también es importante identificar las características de abuso de poder de parte de los agresores.

En igual sentido, se ha reconocido que en México existe un patrón generalizado de violencia sistémica de género. En materia de violación y violencia sexual en conflictos armados o patrones sistemáticos de violencia, se advirtió que se trata de graves violaciones de derechos humanos que contravienen normas inderogables $\mathrm{y}$ atentan contra la dignidad humana y, por ende, exigen la investigación y enjuiciamiento oportuno de los hechos. En esto deben observarse los parámetros en el estándar de prueba en cuestiones de violencia sexual, sin esperar pruebas directas o gráficas, de modo que el dicho de la víctima es una prueba fundamental.

Una característica definitoria de la violencia y tortura que ha establecido la Corte es, precisamente, el contexto de intencionalidad, el sufrimiento humano y la finalidad del acto, tendente a la subordinación de la víctima, pues con ello se anula la libre decisión de la mujer en materia de violación sexual al perder el control absoluto sobre decisiones tan personales e íntimas como sus funciones corporales más básicas.

\subsection{Las reparaciones con perspectiva de género}

Los criterios apuntan en dos direcciones. De un lado, el reconocimiento de que puede existir un sufrimiento directo en los familiares de las víctimas, de forma que, igualmente, son sujetos de protección dentro de las reparaciones y deben ser reconocidos como tales. Por otro lado, se extrae también la necesidad de analizar el contexto de violación de derechos, con miras a ponderar y fijar adecuadamente las reparaciones, desde la indemnización, hasta todas aquellas medidas que implican garantías de no repetición.

Así, la jurisprudencia reconoce el elemento contextual que exigen las investigaciones con perspectiva de género, para identificar los patrones de la zona donde ocurren los hechos. Asimismo, se ha impulsado la necesidad de disponer de los recursos humanos, económicos, logísticos, científicos de cualquier índole, para el éxito de investigaciones en materia de desaparición, con mayor urgencia cuando se trate de niñas. También se identificó la inmediata necesidad de capacitar a los servidores públicos, para desarrollar su actuación con enfoque de género.

La jurisprudencia de la Corte IDH, aporta como elemento diferenciador que las investigaciones tomen en cuenta el patrón sistemático de la violencia en la época en que ocurren los hechos, 
para observar los impactos diferenciados con motivo de la violencia sufrida por la niñez y la mujer. Desde esta perspectiva la investigación con perspectiva de género permite considerar condiciones especiales de vulnerabilidad, por ejemplo, cuando deba tenerse en cuenta la cosmovisión indígena de la víctima, o bien cuando existan sujetos de protección especial como los niños y niñas, casos en los que será necesario asegurar que las víctimas sean escuchadas, a través del personal debidamente preparado para atenderles y adaptar los procesos a sus necesidades particulares, con el fin de evitar su revictimización.

Como puede verse, la importancia del tema surge de indicadores contextuales que apuntan a la necesidad de desarticular situaciones, de diversa índole, que han perpetuado condiciones estructurales de discriminación y desigualdad en perjuicio de diferentes derechos y libertades de la mujer. En ese sentido la jurisprudencia de la Corte Interamericana funciona como vaso comunicante a los demás jueces nacionales a partir de lo cual pueden transformarse las relaciones de exclusión social y subordinación que continúan vigentes. Ello solo es posible y visible desde los diversos casos contenciosos que existen en cada país de América Latina.

Así, las tres líneas de acción desarrolladas por la jurisprudencia de la Corte Interamericana de Derechos Humanos constituyen puertas de acceso hacia la transformación cultural de la violencia de género en América Latina e, igualmente, son elementos interpretativos que deben aterrizarse en los casos concretos en la jurisdicción mexicana, en donde la violencia de género es patente. En tal sentido, serían especialmente útiles dicha herramientas para que la judicatura y todas las instancias procuradoras e impartidoras de justicia, tengan parámetros claros para entender bajo qué condiciones debe analizarse la existencia de relaciones de subordinación, con una perspectiva de género.

\section{CONCLUSIONES}

Es incuestionable que la incidencia de la violencia contra la mujer va al alza y que los espacios en que esta se presenta son tan diversos como las formas de manifestación de la violencia misma. A esto se suma que los estereotipos de género que son reproducidos por la familia, en la escuela, los medios de comunicación, la iglesia y que constituyen el sustento de las desigualdades de poder, no han desaparecido y pareciera que las campañas para erradicarlos, en vez de lograr su objetivo, inciden proporcionalmente en su incremento.

A pesar de los esfuerzos realizados para prevenir, atender, sancionar y erradicar la violencia, el porcentaje de mujeres que sufre o ha sufrido situaciones de violencia hace manifiesto que el Estado tiene mucho por hacer para estar en posibilidad e garantizar a la mujer el acceso a una vida libre de violencia.

Las autoridades deben atender a nuevas fórmulas y esquemas de socialización que permitan prevenir las conductas generadas con base en los estereotipos de género, con el fin de identificarlas y evitar el trato discriminatorio de que son objeto las mujeres, incluso, en los procesos de investigación de las violaciones que denuncian, para, partiendo de ello, se les pueda garantizar un acceso a la justicia eficaz con medidas de reparación efectivas. Esto exige una participación activa de la judicatura con un enfoque de derechos humanos, por cuanto su tarea principal radica en hacerlos efectivos.

La exposición a la violencia en que se encuentra sujeta la mujer precisa de un replanteamiento en la forma de acceder a la justicia. En tal virtud, la jurisprudencia desarrollada por la Corte IDH ofrece una aproximación sensible sobre estas problemáticas, que debe hacerse efectiva por medio de su conocimiento y aplicación por los operadores jurídicos de todas las instituciones. En el desarrollo de la actividad jurisdiccional es relevante que sean observados los criterios jurisprudenciales que conllevan un avance a la protección de la mujer contra la violencia de género, en el entendido de que solo así se podrán identificar las causas de violencia y tomar medidas de posible erradicación.

El conocimiento clasificado de la línea jurisprudencial que aquí se ofrece, busca diseccionar los datos más importantes, con el objeto de hacerlos accesibles $y$, que su conocimiento y difusión, repercuta de forma inmediata en la materialización de dichos criterios dentro de la jurisdicción nacional, en el tema prioritario de atención que amerita la 
superación de los escenarios de violencia que vive la mujer y, con ello, abonar a la reducción de la tasa de impunidad que la caracteriza.

\section{REFERENCIAS BIBLIOGRÁFICAS}

- Banco Mundial (2019). Tasa de mortalidad materna (estimado mediante modelo, por cada 100.000 nacidos vivos). Grupo Banco Mundial Disponible en: https://datos. bancomundial.org/indicador/SH.STA. MMRT

- Bobbio, N. (1991). El tiempo de los derechos. Madrid: Sistema.

- CEDAW/C/MEX/CO/9. (2018). Observaciones finales sobre el noveno informe periódico de México, 25 de julio de 2018, Convención sobre la Eliminación de todas las Formas de Discriminación contra la Mujer del Comité para la Eliminación de la Discriminación contra la Mujer.

- COMISIÓN DE DERECHOS HUMANOS, NACIONES UNIDAS. (2005). Conjunto de principios actualizado para la protección y la promoción de los derechos humanos mediante la lucha contra la impunidad. Sitio Web: https://documents-dds-ny. un.org/doc/UNDOC/GEN/G05/109/03/ PDF/G0510903.pdf?OpenElement

- CORTE IDH. Caso Loayza Tamayo. vs. Perú. Fondo. Sentencia de 17 de septiembre de 1997. Serie C. No. 33.

- -------. Caso Benavides Cevallos. vs. Ecuador. Fondo, reparaciones y costas. Sentencia de 19 de junio de 1998. Serie C. No. 38.

- ------. Caso Myrna Mack Chang vs. Guatemala. Fondo, reparaciones y costas. Sentencia de 25 de noviembre de 2003. Serie C. No. 101.

- ------. Caso Maritza Urrutia vs. Guatemala. Fondo, reparaciones y costas. Sentencia de 27 de noviembre de 2003. Serie C. No.103.
- --------. Caso de la Cruz Flores vs. Perú. Fondo, reparaciones y costas. Sentencia de 18 de noviembre de 2004. Serie C. No. 115.

- --------. Caso de las Hermanas Serrano Cruz vs. El Salvador. Fondo, reparaciones y costas. Sentencia de 1 de marzo de 2005. Serie C. No.120.

- --------- Caso del Penal Miguel Castro Castro vs. Perú. Fondo, reparaciones y costas. Sentencia de 25 de noviembre de 2006. Serie C. No. 160.

- -------. Caso González y otras ("Campo Algodonero"). vs. México. Excepción preliminar, fondo, reparaciones y costas. Sentencia de 16 de noviembre de 2009. Serie C. No. 205.

- -------- Caso de la Masacre De Las Dos Erres vs. Guatemala. Excepción preliminar, fondo, reparaciones y costas. Sentencia de 1 de marzo de 2005. Serie C. No. 120.

- -------. Caso Fernández Ortega y otros vs. México. Excepción preliminar, fondo, reparaciones y costas. Sentencia de $24 \mathrm{de}$ noviembre de 2009. Serie C. No. 211.

- --------. Caso Rosenda Cantú y otra vs. México. Excepción preliminar, fondo, reparaciones y costas. Sentencia de 31 de agosto de 2010. Serie C. No. 216.

- --------. Estatuto de la Corte IDH. http:// www.corteidh.or.cr/estatuto.cfm

- ENDIREH. (2016). Encuesta Nacional sobre la Dinámica de las Relaciones en los Hogares Pp. 13-16. INEGI. (2017) Disponible en: https://www.inegi.org.mx/ contenidos/programas/endireh/2016/ doc/endireh2016_presentacion_ejecutiva. pdf

- INMUJERES-SEGOB. (2017). La violencia 
feminicida en México, aproximaciones y tendencias 1986-2016. México: ONU Mujeres.

- LATINOBARÓMETRO.

(2019).

Latinobarometro 2018. Corporación Latinobarómetro. Disponible en: http:// www.latinobarometro.org/lat.jsp

- ORGANIZACIÓN DE LOS ESTADOS AMERICANOS. (1969). Convención Americana Sobre Derechos Humanos (Pacto De San José). https://www.oas.org/dil/ esp/tratados_b-32_convencion_americana_ sobre_derechos_humanos.htm

- ONU Mujeres. (2017). La violencia feminicida en México, aproximaciones y tendencias 1985-2016, México. Ciudad de México: INMUJERES-SEGOB. Sitio Web: https://mexico.unwomen.org/ es/digiteca/publicaciones/2017/12/ violencia-feminicida

- ONU MÉXICO. (2018). La violencia contra las mujeres no es normal ni tolerable. $\mathrm{ONU}$
México. Disponible en: http://www.onu. org.mx/la-violencia-contra-las-mujeresno-es-normal-ni-tolerable/

- Secretaría de Seguridad Ciudadana (2019). Informe sobre violencia contra las mujeres. Incidencia delictiva y llamadas de emergencia 9-1-1. Disponible en: https://drive.google.com/file/d/1nfC8tMPcIxCuaCMEFoPoO9LnVzFCKu8/ view

- Suprema Corte de Justicia de la Nación. (2015). Protocolo para juzgar con perspectiva de género. México: Suprema Corte de Justicia de la Nación. Disponible en: https://www.sitios.scjn.gob.mx/ codhap/sites/default/files/archivos/ paginas/Protocolo_perspectiva_de_genero_ REVDIC2015.pdf

- Zepeda, R. (2018). Siete tesis explicativas sobre el aumento de la violencia en México. Revista Política y Gobierno, XXV (1), 185-211. 